Journal of Bangladesh Academy of Sciences, Vol. 39, No. 1, 59-64, 2015

\title{
MICROSTRUCTURE AND MAGNETIC PROPERTIES OF SOFT NICKEL FERRITE
}

\author{
MAHABUB ALAM BHUIYAN*, SHEIKH MANJURA HOQUE ${ }^{1}$ AND \\ SHAMIMA CHOUDHURY \\ Department of Physics, University of Dhaka, Dhaka-1000, Bangladesh
}

\begin{abstract}
Polycrystalline $\mathrm{NiFe}_{2} \mathrm{O}_{4}$ samples were prepared from analytical grade powder of $\mathrm{NiO}$ and $\mathrm{Fe}_{2} \mathrm{O}_{3}$ by conventional double sintering technique. The samples were sintered at $1000-1400^{\circ} \mathrm{C}$. The scanning electron micrographs (magnification $\times 10000$ ) of the samples revealed that the grain size increases and the porosity decreases with the increase in sintering temperature. These changes in microstructure, grain size and porosity with sintering temperature have great influence on the magnetic properties of $\mathrm{NiFe}_{2} \mathrm{O}_{4}$. Complex permeability ( $\mu^{\prime}$ ) over the frequency range from $1 \mathrm{kHz}$ to $13 \mathrm{MHz}$ for the samples at different sintering temperatures $\left(1000-1400^{\circ} \mathrm{C}\right)$ has been observed. Variation of permeability with the applied temperature has been observed at various sintering temperature from which Curie temperature have been calculated. Decreased value of Curie temperature $\left(T_{c}\right)$ has been found with the increase of sintering temperature.
\end{abstract}

Key words: Microstructure, Magnetic properties, Soft nickel ferrite

\section{INTRODUCTION}

For the last few years the soft ferrites have been extensively studied due to their excellent micro structural, magnetic and transport properties. Among the ferrites, the spinel type ferrites are particularly important. They consist of spontaneously magnetized domains and show the phenomena of magnetic saturation and hysteresis. The spinel ferrites possess properties of both magnetic materials and insulators. They can be used as electromagnetic wave absorbers or electromagnetic interference (EMI) suppressor in the $\mathrm{MHz}$ frequency range like the TV ghost suppressor (Green et al. 1964, Goldman 1990, Verma et al. 2003, Han et al. 1995, Luo et al. 2000, Meshram et al. 2002). Ferrites are also used in camouflaging military aircrafts and missiles against radar detection (Meshram et al. 2002). Among the spinel type ferrites, nickel ferrite is a suitable material for microwave applications (Nicolas 1980). It is noted for its high Curie temperature, high resistivity, good temperature stability of saturation magnetization and semiconducting behavior (Vladikova et al. 1989). Such properties make nickel ferrites prominent in recent applications and growing interests to the researchers because these materials can be sintered at relatively low temperature with a wide range of compositions.

*Corresponding author < mail2mahabub@gmail.com>.

${ }^{1}$ Materials Science Division, Atomic Energy Centre, Dhaka-1000. 
Effect of sintering temperature on microstructures, magnetic properties, apparent density and transport properties of $\mathrm{NiFe}_{2} \mathrm{O}_{4}$ has been reported for the samples prepared from nano size powder of $\mathrm{NiO}$ and $\mathrm{Fe}_{2} \mathrm{O}_{3}$ (Bhuiyan et al. 2010, Choudhury et al. 2011). This paper focuses its discussion on the influence of sintering temperature on the micro structural and magnetic properties of $\mathrm{NiFe}_{2} \mathrm{O}_{4}$ synthesized from analytical grade powder (bulk) of $\mathrm{NiO}$ and $\mathrm{Fe}_{2} \mathrm{O}_{3}$.

\section{MATERIALS AND METHOD}

Polycrystalline $\mathrm{NiFe}_{2} \mathrm{O}_{4}$ samples were prepared through the solid-state reaction using conventional double sintering ceramic technique from analytical grade powder of $\mathrm{NiO}$ and $\mathrm{Fe}_{2} \mathrm{O}_{3}$. The purity of the constituent elements was $\mathrm{NiO}(99.9 \%)$ and $\mathrm{Fe}_{2} \mathrm{O}_{3}(99.9 \%)$ and was obtained from E. Mark of Germany at the Materials Science Division, Atomic Energy Center Dhaka. After thorough mixing, the powder was presintered at $1100^{\circ} \mathrm{C}$ for 3 hours. The presintered ferrite powder was crushed and mixed with 1 wt. \% polyvinyl alcohol (PVA) as a binder and uniaxially pressed into toroid and pellets. The compacts were successively sintered in a muffle furnace in air from the temperature range from 1000 to $1400^{\circ} \mathrm{C}$ for 4 hours to eliminate the PVA, and finally, the furnace was cooled down to room temperature. The scanning electron micrographs with magnification $\times$ 10000 have been studied by using a scanning electron microscope (SEM). Frequency dependence of permeability was measured up to $13 \mathrm{MHz}$ by an inductance analyzer named WAYNE KERR INDUCTANCE ANALYZER 3255B (Wayne Kerr Electronics Inc., Woburn, MA, USA). Variations of permeability with temperature were measured according to the experimental setup described elsewhere from which Curie temperatures have been determined (Cedillo et al. 1980).

\section{RESULTS AND DISCUSSION}

Fig. 1 shows the scanning electron micrographs of polycrystalline $\mathrm{NiFe}_{2} \mathrm{O}_{4}$ prepared from the bulk powder of $\mathrm{NiO}$ and $\mathrm{Fe}_{2} \mathrm{O}_{3}$ with magnification $\times 10000$ sintered at various temperatures.

From the SEM micrographs, it is observed that grain size increases with increasing sintering temperature. Moreover, the samples sintered at higher temperatures (1300, $\left.1400^{\circ} \mathrm{C}\right)$ are more densified than the samples sintered at lower temperatures $(1000,1100$, $1200^{\circ} \mathrm{C}$ ). This is due to the porosity of the samples sintered at lower temperatures are predominately intergranular, whereas the porosity of the samples sintered at higher temperatures is located at grain boundaries and many of the very small pores disappear through diffusion kinetics. That is why the grain size increases and the number of grain 
boundary decreases with the increase in sintering temperature and consequently the porosity decreases (Bhuiyan et al. 2012).

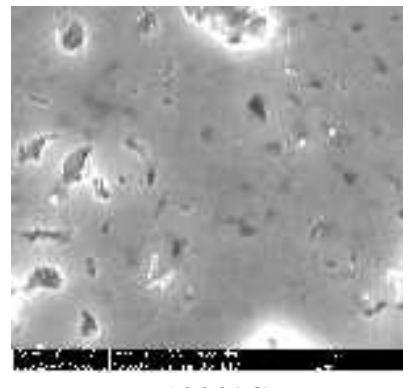

$1000^{\circ} \mathrm{C}$

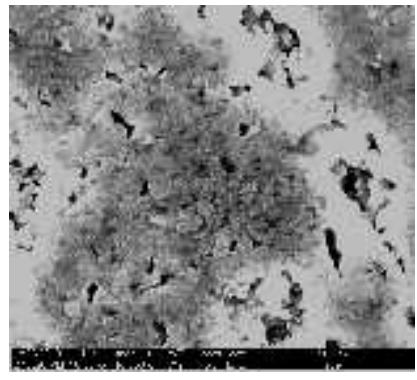

$1100^{\circ} \mathrm{C}$

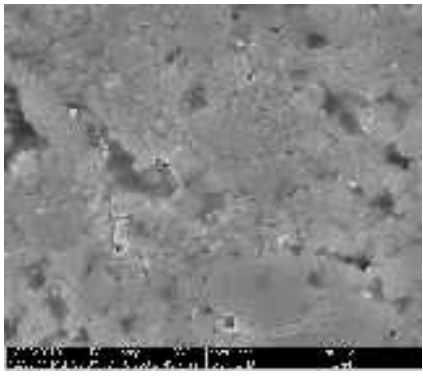

$1200^{\circ} \mathrm{C}$

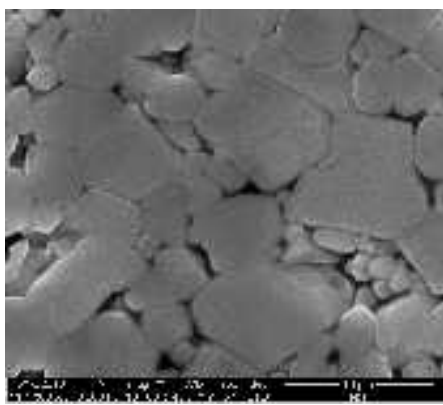

$1300^{\circ} \mathrm{C}$

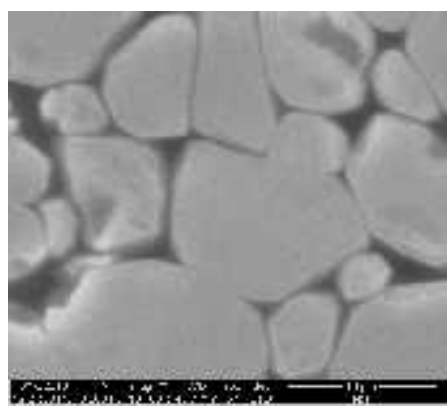

$1400^{\circ} \mathrm{C}$

Fig. 1. SEM micrographs of polycrystalline $\mathrm{NiFe}_{2} \mathrm{O}_{4}$ prepared from bulk powder of $\mathrm{NiO}$ and $\mathrm{Fe}_{2} \mathrm{O}_{3}$ with magnification $(\times 10000)$ at various sintering temperatures.

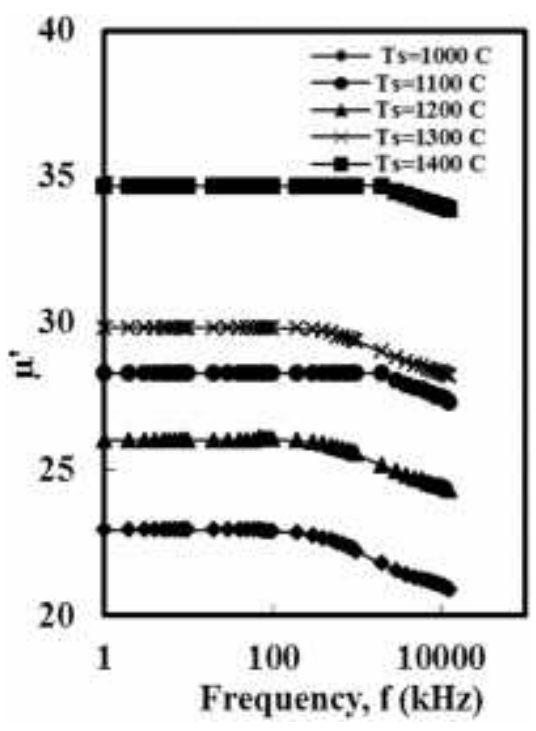

Fig. 2. Frequency dependent real part of initial permeability for various sintering temperature.

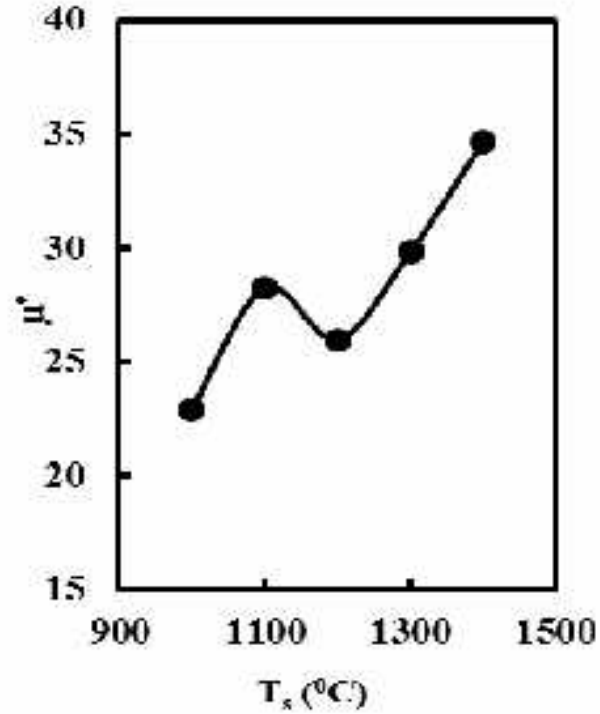

Fig. 3. Sintering temperature dependent real part of permeability ( ') at $\mathrm{f}=1 \mathrm{kHz}$. 
Frequency dependent real part of initial permeability $\left(\mu^{\prime}\right)$ of the samples at different sintering temperatures is presented in Fig. 2. The flat $\mu^{\prime}$ region up to the frequency where it starts declining rapidly gives the compositional stability and quality of prepared ferrite and is known as the zone of utility of the ferrite (Bhuiyan et al. 2010). Fig. 3 represents the sintering temperature dependent real part of permeability ( $\left.{ }^{\prime}\right)$ at $f=1 \mathrm{kHz}$. From Figs 2 and 3 it is observed that the permeability increases with the increase in sintering temperature. This may be attributed due to the fact that at higher sintering temperature the grain size is larger and the density is higher which gives greater the grain to grain continuity in magnetic flux leading to higher permeability (Verma and Chatterjee 2006).

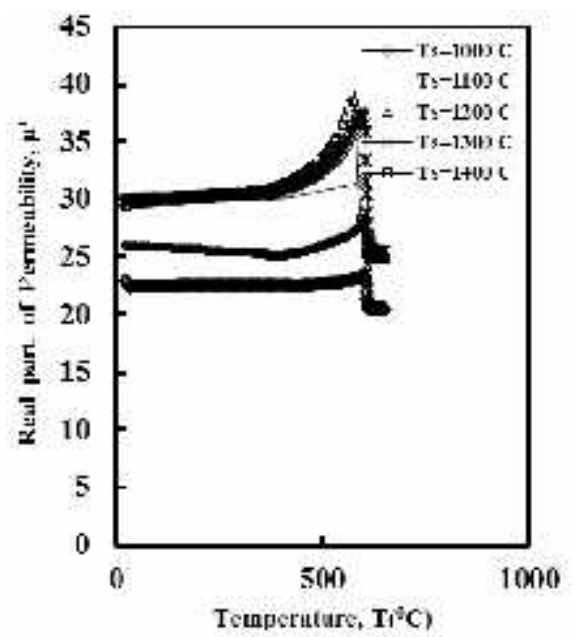

Fig. 4. Temperature dependent real part of initial permeability for various sintering temperature.

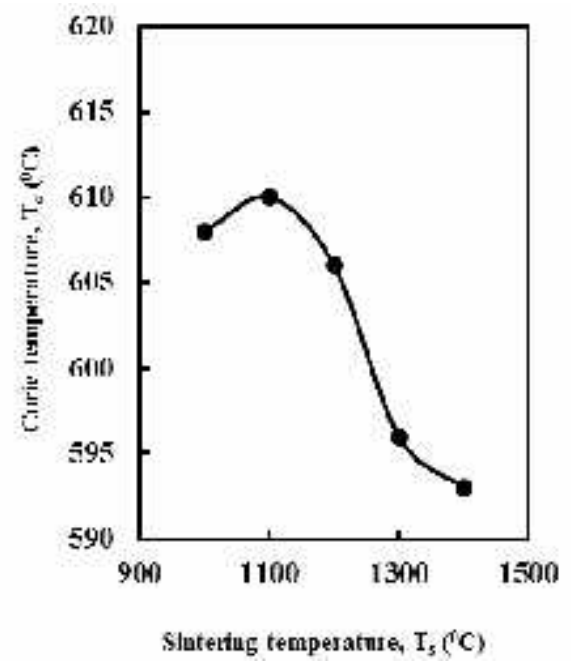

Fig. 5. Sintering temperature dependent Curie temperature.

The variation of initial permeability $\left({ }_{i}\right)$ with temperature is shown in Fig. 4. The initial permeability $(\mathrm{i})$ slowly increases with the temperature, reaches a maximum and then sharply drops to zero at Curie temperature. The tailing effect is not observed indicating the formation of single phase of the ferrites. The increase in initial permeability ( $\mathrm{i}$ ) with temperature can be explained as follows - the anisotropy field usually decreases with temperature much faster than saturation magnetization $\left(\mathrm{M}_{\mathrm{s}}\right)$. The high value of initial permeability $\left(_{i}\right.$ ) corresponds to zero point in anisotropy caused by presence of $\mathrm{Fe}^{2+}$ in the samples (Jadhav 2001). The ${ }_{i}-\mathrm{T}$ variation does not show a second maximum, which is due to excess formation of $\mathrm{Fe}^{2+}$ in the samples. Thus the samples are homogeneous with only one temperature (Curie temperature) at which crystal anisotropy passes through zero value.

Sintering temperature dependent Curie temperature has been presented in Fig. 5. From Fig. 5 decrease in Curie temperature has been found with the increase in sintering 
temperature. This variation of Curie temperature occurs because with the variation of sintering temperature valence state of the cations like $\mathrm{Fe}^{3+} \leftrightarrow \mathrm{Fe}^{2+}$ and $\mathrm{Ni}^{2+} \leftrightarrow \mathrm{Ni}^{3+}$ occurs.

\section{CONCLUSIONS}

Variation of microstructure and magnetic properties of $\mathrm{NiFe}_{2} \mathrm{O}_{4}$ synthesized from analytical grade powder of $\mathrm{NiO}$ and $\mathrm{Fe}_{2} \mathrm{O}_{3}$ on sintering temperature were confirmed in this research work. The grain size increases and porosity decreases with the increase in sintering temperature and the samples become more densified at higher sintering temperature. Enhancement of real part of initial permeability as a function of frequency has been observed with the increase in sintering temperature, which is due to the increase in grain growth of the samples. Temperature dependent real part of initial permeability has been observed at various sintering temperature and gives the manifestation of Hopkinson effect. With the increase in sintering temperature Curie temperature decreases which may be due to the valance state of the cations.

\section{ACKNOWLEDGMENT}

Laboratory facilities of Materials Science Division, Atomic Energy Centre, Dhaka (AECD) are acknowledged.

\section{REFERENCES}

Bhuiyan, M. A., S. M. Hoque and S. Choudhury. 2010. Effect of sintering temperature on microstructure and magnetic properties of $\mathrm{NiFe}_{2} \mathrm{O}_{4}$ prepared from nano size powder of $\mathrm{NiO}$ and $\mathrm{Fe}_{2} \mathrm{O}_{3}$. J. Bangladesh Acad. Sci. 34: 189-195.

Cedillo, E., J. Ocampo, V. Rivera and R. Valenzuela. 1980. An apparatus for the measurements of initial magnetic permeability as a function of temperature. J. Phys. E: Sci. Instrum. 13: 383386.

Choudhury, S., M. A. Bhuiyan and S. M. Hoque. 2011. Effect of Sintering Temperature on Apparent Density and Transport Properties of $\mathrm{NiFe}_{2} \mathrm{O}_{4}$ : Synthesized from Nano Size Powder of $\mathrm{NiO}$ and $\mathrm{Fe}_{2} \mathrm{O}_{3}$. J. Int. Nano let. 1: 111-116.

Goldman, A. 1990. Modern ferrite technology. Springer, New York.

Green, J. J., J. S. Waugh and B. J. Healy. 1964. Microwave Properties of Fine Grain Nickel Ferrite. J. Appl. Phys. 35: 1006-1007.

Han, K. C., H. D. Choi, T. J. Moon and W. S. Kim. 1995. Dispersion characteristics of the complex permeability-permittivity of Ni-Zn ferrite-epoxy composites. J. Mater. Sci. 30: 3567-3570.

Luo, H. Y., Z. X. Yue and J. Zhou. 2000. Synthesis and high-frequency magnetic properties of sol gel derived Ni Zn ferrite forsterite composites. J. Magn. Magn. Mater. 210: 104-108.

Meshram, M. R., N. K. Agrawal, B. Sinha and P. S. Misra, 2002. A study on the behaviour of Mtype barium hexagonal ferrite based microwave absorbing paints. Bull. Mater. Sci. 25: 169173.

Nicolas, J. 1980. Ferromagnetic materials. North-Holland, Amsterdam.

Jadhav, S. A. 2001. Magnetic properties of $\mathrm{Zn}$ substituted Li-Cu ferrites. J. Magn. Magn. Mater. 224: 167-172. 
Verma, A., A. K. Saxena and D. C. Dube 2003. Microwave permittivity and permeability of ferrite-polymer thick films. J. Magn. Magn. Mater. 263: 228-234.

Verma, A. and R. chatterjee. 2006. Effect of zinc concentration on the structural, electrical and magnetic properties of mixed $\mathrm{Mn}-\mathrm{Zn}$ and $\mathrm{Ni}-\mathrm{Zn}$ ferrites synthesized by the citrate precursor technique. J. Magn. Magn. Mater. 306:313-320.

Vladikova, D., H. Yonchev, L. Ilkov and S. Karbanov. 1989. Substituted Nickel Ferrites for Microwave Frequencies Designed by Experimental Statistical Modeling. J. Magn. Magn. Mater. 78: 420 .

(Received revised manuscript on 19 November, 2014) 